\title{
Editor's audit report for 1996
}

The best form of audit in sport is performance. No fitness test, time trial, or practice match can be a substitute for the real thing. Similarly with a journal. Every reader judges the quality of a journal by what arrives through the letter box. You are the real judge of performance. We have some proxy measures of quality that we record and that are of some value because they allow both you, the reader, and us to look at the number of papers we receive, how we deal with them, and how others appraise the journal. Unfortunately, owing to the publication dates of the journal, we were unable to include these details in our March edition.

During 1996 we received a total of 184 manuscripts. This included original papers, reviews, short reports, and letters (table 1). During the year we published 68 original articles, eight reviews, and six letters. Of unsolicited manuscripts, this represents an acceptance rate of $33 \%$. We continue to receive work from many countries throughout the world but predominantly from the United Kingdom (table 2). The journal now has a citation index of 0.315 , which ranks us in the middle of the pack (table 3 ). There is a lag time with a citation index so this represents the citation of the journal in past years and the status of the journal should be reflected by change in the future.

We are very keen that authors get a decision as soon as possible after submission and we encourage our referees to respond rapidly. For some papers of a specialist nature it has been difficult to identify appropriate referees and if a referee declines, this delays the process. The mean length of time from receipt to decision is 73 days. We inherited a backlog of papers initially but we are now up to date and almost all papers in the December issue of the Journal had been accepted during the previous year. We had two problems with the December 1996 edition. Firstly, it was late

Table 1 Articles submitted by category

\begin{tabular}{lc}
\hline Category & 1996 \\
\hline Original papers & 93 \\
Case reports & 22 \\
Short reports & 20 \\
Editorials & 12 \\
Reviews & 14 \\
Letters & 12 \\
Occasional pieces & 2 \\
Clinical tests & 1 \\
Fillers & 8 \\
Total & 184 \\
\hline
\end{tabular}

Table 2 Geographical distribution of submissions

\begin{tabular}{lc}
\hline Area & 1996 \\
\hline United Kingdom & 110 \\
Western Europe & 5 \\
Eire & 2 \\
Germany & 1 \\
Israel & 2 \\
Italy & 6 \\
Spain & 6 \\
Turkey & 20 \\
USA \& Canada & 3 \\
Japan & 16 \\
Australasia & 7 \\
Scandinavia & 4 \\
Asia & 2 \\
Africa &
\end{tabular}

Table 3 Citation index and half life for sport sciences journals 1995

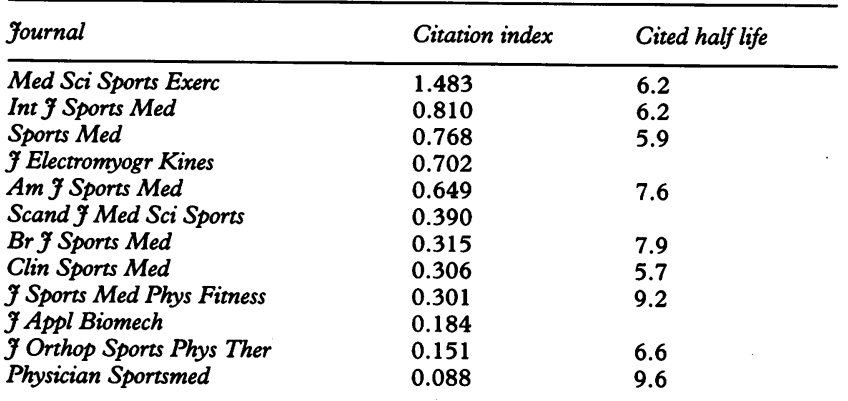

and, secondly, some of the abstracts from the BASM congress were not included. We intend to have the Journal delivered in time in future and apologise to those who had to wait a little longer to see their abstract in print.

Overall we believe that 1996 was a successful year for the Journal. The credit for this is due primarily to the contributors. Your high quality work makes ours a high quality journal. We look forward to continuing to receive your work in the future. The unsung heroes of a journal are the referees who read through all the manuscripts and often give detailed and very helpful advice to authors (see $p$ 166). We could not manage without them. Our editorial board have also had to work hard throughout the year, and we have had many helpful suggestions from our readers. Professor Ron Maughan, our associate editor has been wonderful, and we could not have done without Mavis Burrell our editorial assistant whose knowledge and experience have been indispensable. 